\title{
Technology acceptance model in technology-enhanced OCLL contexts: A self-determination theory approach
}

\author{
Somayeh Fathali, Takeshi Okada \\ Graduate School of International Cultural Studies, Tohoku University, Japan
}

One of the crucial issues for successful technology-enhanced out-of-class language learning (OCLL) is the learners' continuance intention to use technology. Considering the strong mutual relationship between learners' intention and motivation, the present study extended the technology acceptance model (TAM) with the self-determination theory (SDT) to investigate Japanese EFL learners' intention to use learning technologies for OCLL. The study was conducted in a technology-enhanced OCLL environment using a web-based e-portfolio system. The hypothesised model included two principal antecedents of behavioural intention introduced by TAM - perceived usefulness and perceived ease of use - in addition to the three psychological needs for competence, autonomy, and relatedness introduced by SDT. Path analysis was conducted to find the multivariate relationships between the constructs in the model based on the collected data from 162 Japanese EFL learners. The results indicated that SDT determinants could significantly predict perceived usefulness and perceived ease of use, among which perceived competence was the most influential factor. Furthermore, perceived usefulness highly influenced the learners' intention to continue technology-enhanced OCLL, which in turn influenced their actual usage of the system.

\section{Introduction}

The efficient implementation of learning technologies supports both inside and beyond classroom learning opportunities and maximizes students' learning outcomes in different ways (Chapelle, 2010; Fathali \& Okada, 2016; Zhao \& Lai, 2007). Although many English as a Foreign Language (EFL) teachers and instructors try to incorporate technological tools in the teaching contexts and benefit from the effectiveness of information and communication technologies (ICTs), this attempt is mostly restricted to inside the classrooms, and technology is not efficiently implemented in designing teacher-supported learning contexts beyond the classroom (Stockwell, 2013; Whittaker, 2013). Findings from previous studies provide evidence that emerging technology offers several new resources to enhance self-regulated language learning beyond the classroom (Nunan \& Richards, 2015; Reinders, 2014). However, today’s computer-assisted language learning (CALL) lacks studies that investigate technology-enhanced out-of-class language learning (OCLL) contexts (Benson, 2001, 2011; Richards, 2015; Stockwell, 2013). Furthermore, there is a need to examine influential conditions and factors on students' actual practice with the available technologies beyond the classroom in different regional contexts, especially Asian countries (Steel \& Levy, 2013; Thomas, 2017). One of the noteworthy factors in this domain that requires further investigation is the language learners' acceptance of the technology and their intention to continue using technology-enhanced OCLL (Lai, Li, \& Wang, 2017; Lee \& Lehto, 2013; Mobarhan, Majidi, \& Abdul Rahman, 2014; Reinders, 2014; Richards, 2015).

In Japan, the setting of the present study, in spite of numerous CALL-related studies, there is still a need to investigate more about Japanese students' language learning beyond the borders of the actual classroom (Stockwell, 2013; Thomas, 2017). Although Japan is ranked among the top ten countries in terms of ICT access and usage (International Telecommunication Union, 2017), and most of the universities are equipped with highly designed CALL classrooms, Japanese students' digital literacy lags behind students of other advanced countries (Cote \& Milliner, 2016). As stated in Cote and Milliner (2016), "The Organization for Economic Co-operation and Development (OECD, 2015) released a critical statement on the literacy of Japanese youth, noting that 25\% (age 16-29) lack basic computer skills” (p. 127). Japanese students are assumed to be using ICT excessively in their everyday life, yet they hardly use their daily life ICT skills for using technology for learning (Cote \& Milliner, 2016; Gobel \& Kano, 2014; Lockley \& Promnitz-Hayashi, 2012). The lack of adequate ICT engagement in high schools results in students having low confidence for 
using digital technologies upon entering university, which affects their ability to independently use technology for language learning. Moreover, Fukuda and Yoshida (2013) found that Japanese students are not motivated enough to expand their out-of-class language learning time, which ranges only between zero to an hour a week. Accordingly, this study focuses on examining Japanese university students' acceptance of technology for language learning and their intention to further their independent use of technology beyond the classroom through the integration of the technology acceptance model (TAM) and the self-determination theory (SDT).

TAM (Davis, 1989) is one of the commonly applied models in the ICT domain that aims to explain the behavioural intention of users to continue using technologies. Users' behavioural intention reflects the extent to which they intend to do an activity, which is normally followed by the occurrence of the actual action (Davis, 1989). According to TAM, users' acceptance of a system and their behavioural intention to continue using it largely depends on two principal determinants of perceived usefulness and perceived ease of use. Davis (1989) defines perceived usefulness as "the degree to which a person believes that using a particular system would enhance his/her job performance"; and perceived ease of use as "the degree to which a person believes that using a particular system would be free of physical and mental effort” (p. 320). The basic TAM without external variables gives a general explanation about the users' behaviour. The core idea of the model is that perceived usefulness and perceived ease of use mediate the relationship between the external variables such as the features of the system and the users' behavioural intention to continue using that system, which in turn affects the actual system usage (Davis, 1989; Li \& Huang, 2009; Venkatesh \& Davis, 2000). The external variables have crucial roles in explaining the users' acceptance and their actual use of the system (Davis, Bagozzi, \& Warshaw, 1992; Venkatesh \& Davis, 2000). So far, numerous studies extended the basic TAM introduced by Davis (1989) by incorporating various external variables into the basic model (as antecedents of perceived ease of use and perceived usefulness) and investigated the effect of different system features and users' behaviours on their intention to use technologies. In a review of 107 studies that added external variables to the basic TAM and proposed new models, Abdullah and Ward (2016) found five excessively and commonly used variables for the extension - self-efficacy, subjective norm, perceived enjoyment, computer anxiety, and computer use experience. Although motivation is a crucial external variable, only perceived enjoyment as an intrinsic motivation factor was examined repeatedly, and there is still more to investigate about other motivational variables.

Based on the cognitive theories of motivation and action, being motivated to act is equal to having an intention to engage in an action (Deci, 1975). Therefore, due to the strong mutual relationship between learners' motivation and their intention for an action (Deci, 1975; Ellis, 1994), and the roots of TAM in motivational models (Davis et al., 1992; Ho, 2010; Muthitacharoen et al., 2006; Roca \& Gagné, 2008), this study extended the basic TAM with a motivational theory, that is, SDT, introduced by Deci and Ryan (1985), to investigate factors affecting Japanese EFL learners' intention to continue technology-enhanced language learning beyond the classroom.

Over decades of research on motivation, researchers have proposed a number of motivation theories (Ajzen \& Fishbein, 1980; Deci \& Ryan, 1985; Dornyei, 1998; Pintrich \& Schunk, 2002). In spite of having some differences, the proposed theories share overlapping concepts and characteristics. The theories differ mainly in their starting points, as they may have roots either in the learners' cognitive beliefs (internal factors) or contextual factors (Dornyei, 1998; Grabe, 2009). However, well-established motivation theories such as achievement theory, attribution theory, goal orientation theory, social-cognitive theory, and self-determination theory see motivation arising from cognitive beliefs and expectations (Pintrich \& Schunk, 2002; Schunk \& Zimmerman, 2006). The commonality of these theories is that they are task-dependent and they characterise motivation as the influence of both individuals' cognitive beliefs and environmental factors.

As Dornyei (1998) states "every different psychological perspective on human behavior is associated with a different theory of motivation” (p. 118). Among the proposed theories of motivation, SDT is highly associated with learner autonomy and relates motivation to the students' willingness to take responsibility for their own actions (Dornyei, 1998). Since successful OCLL largely depends on learners' self-determined behaviours and actions (Mobarhan et al., 2014; Reinders, 2014), SDT can provide a good framework for 
OCLL. Moreover, SDT distinguishes between two types of motivation (i.e., extrinsic and intrinsic motivation), which Davis et al. (1992) also highlighted as two important factors for the user's decision to continue using a system. They proposed perceived usefulness as an example of extrinsic motivation and perceived enjoyment as an example of intrinsic motivation. The relationship between the determinants of SDT and TAM have also been successfully confirmed in some previous studies (Lee, Lee, \& Hwang, 2015; Nikou \& Economides, 2017). In addition, the determinants of SDT have been found to be related to the features of technology-enhanced learning environments both in educational settings (Lee et al., 2015; Nikou \& Economides, 2017; Pedrotti \& Nistor, 2016; Zhou, 2016) and non-educational settings (Roca \& Gagné, 2008; Yoon \& Rolland, 2012). Chen and Jang (2010) argue that perceived competence is associated with challenges for learning technical skills in e-learning environments, perceived autonomy with flexible learning, and perceived relatedness with computer-mediated communication and social interaction. Therefore, SDT as one of the most comprehensive theoretical approaches to human motivation that highly corresponds to technology-based learning environments was chosen to extend the basic TAM and propose a new model.

SDT explains the nature of different types of motivation. Extrinsic motivation, also known as controlled motivation, addresses achievements influenced by external factors such as rewards or punishment; whereas intrinsic motivation, also known as autonomous motivation, addresses situations in which the activity is undertaken due to the inherent enjoyment of the activity apart from the outside effects (Vallerand, 1997). Deci and Ryan (1985) discuss the underpinning or supporting effects of extrinsic factors on intrinsic motivation through the sub-theories of organismic integration theory and cognitive evaluation theory.

According to Deci and Ryan (1985), organismic integration theory defines different types of motivation on a continuum that begins with the extrinsic regulation as the least self-determined type of motivation followed by introjected, identified, and integrated types of motivation. Towards the end of the continuum, with the increase in the degree of internalisation, extrinsic motivation is more likely to change to autonomous selfregulated motivation and move toward intrinsic motivation. Moreover, cognitive evaluation theory argues for the significance of contextual support and satisfaction of the essential needs in order to maximize intrinsic motivation. Cognitive evaluation theory focuses on perceived competence, perceived autonomy, and perceived relatedness as the three basic psychological human needs that facilitate intrinsic motivation (Deci \& Ryan, 1985). The need for competence is the individual's need to feel capable of effective performance, participation, and achieving one's goals. The need for autonomy implies the intention to feel free to choose and control one's own actions. And the need for relatedness is to feel connected to others through proper interaction and cooperation (Vallerand, 1997). Overall, after many years of research on the importance of human motivation, intrinsic motivation has been shown to be the most effective type of motivation resulting in the long-term and better performance of learners in various domains (Baard, Deci, \& Ryan, 2004; Roca \& Gagné, 2008).

Therefore, through the integration of TAM and SDT, this study aims to:

(1) propose an extension of the basic TAM by adding SDT determinants (perceived competence, perceived autonomy, perceived relatedness)

(2) empirically test the relationship between the determinants of SDT and TAM, and investigate how these determinants can explain Japanese EFL learners' intention to continue technology-enhanced OCLL, and more importantly, their actual usage of the learning technologies, in this case a webbased e-portfolio system (the system and its function is explained in the research context).

The findings of this study make two major contributions to the field. First, despite the fact that TAM has been frequently applied in business and organisational settings, its extension in different educational settings still needs to be explored through more empirical research (Edmunds, Thorpe, \& Conole, 2012; PadillaMeléNdez, Del Aguila-Obra, \& Garrido-Moreno, 2013; Tarhini, Scott, Sharma, \& Abbasi, 2015). This need can be attributed to the changing nature of TAM in relation to various features, such as the external variables that can be added to the basic TAM, the context, technological tools, users and activities (Abdullah \& Ward, 2016; Park, Rhoads, Hou, \& Lee, 2014; Tarhini et al., 2015; Teo, Luan, \& Sing, 2008). So far, the basic TAM (Davis, 1989) has been extended by adding different variables, including motivational determinants (Ho, 
2010; Muthitacharoen et al., 2006; Roca \& Gagné, 2008) in work and education-related studies using different technological devices (Ho, 2010; Muthitacharoen et al., 2006; Roca \& Gagné, 2008). However, it has rarely been applied to language learning contexts (Chang, Yan, \& Tseng, 2012), particularly OCLL environments. Among 107 studies reviewed by Abdullah and Ward (2016) that added external variables to TAM, only three studies were in the language learning area which did not concentrate on motivational variables. These studies employed other external variables such as perceived convenience, social influence, and perceived ubiquity (e.g., Chang et al., 2012). Consequently, the present study proposes and tests an extension of TAM with the motivational determinants of SDT in a technology-enhanced OCLL context.

Second, according to Richards (2015), both in and outside of the classroom are the two significant and influential dimensions of successful language learning. Although there are thousands of published studies that focus on what goes on inside technologically equipped language classrooms, very few studies are devoted to the investigation of what goes on beyond the classroom (Benson, 2011; Richards, 2015). Therefore, the findings of this study provide some insights into the crucial issue of the learners' intention in OCLL contexts and aims to improve our understanding of the effective implementation of the learning technologies into these contexts. The following section explains the development of the research model based on the abovementioned theories.

\section{Research model and hypotheses}

Drawing on the two theoretical frameworks of TAM and SDT, this study proposes a model in which the determinants of SDT (three exogenous variables) are predictors of perceived usefulness and perceived ease of use of the system. These firstly predict the learners' behavioural intention toward technology-enhanced OCLL, and then their actual technology usage (Figure 1). Perceived usefulness, perceived ease of use, behavioural intention, and actual technology usage are the endogenous variables of the model.

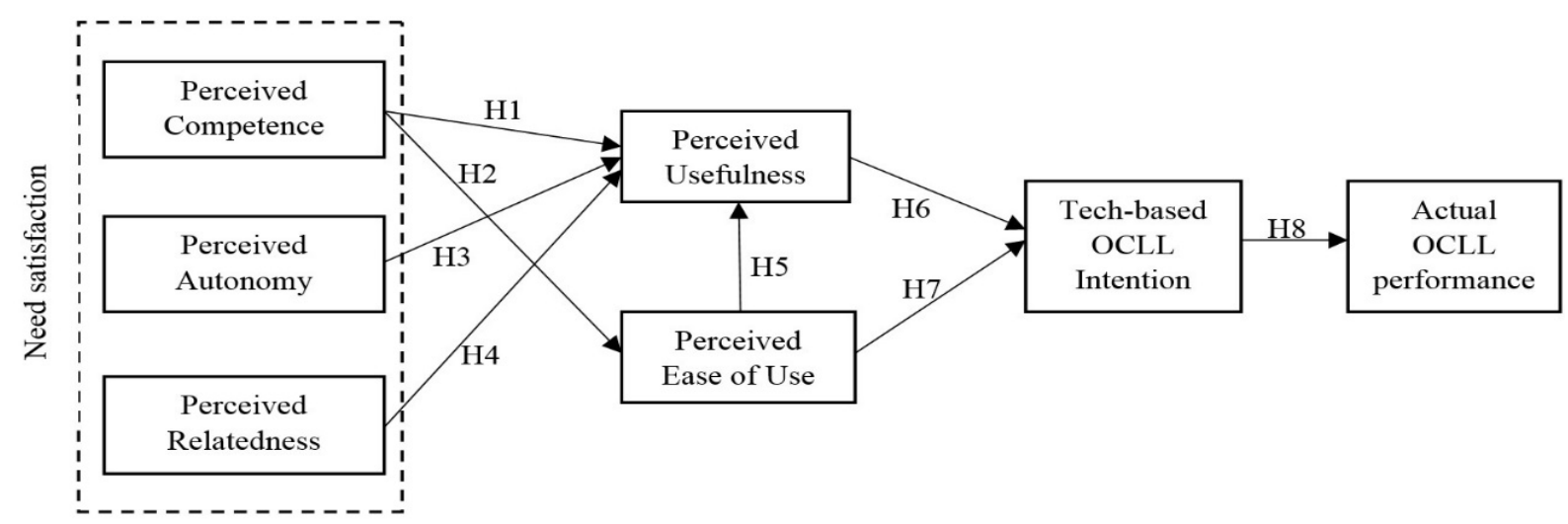

Figure.1. Hypothesised model of the research

Perceived competence in SDT is similar to the concept of self-efficacy defined by Bandura (1986) as "people's judgments of their capabilities to organize and execute courses of action required to attain designated types of performances” (p. 391). People with stronger sense of self-efficacy are less likely to give up on an action (Bandura, 1986). Even though self-efficacy is indirectly associated with actual competence (Dornyei, 1998), it shares common features with perceived competence in SDT (Roca \& Gagné, 2008). Perceived competence reflects the individuals' belief about their ability to perform an action successfully and achieve their goals, which in turn increases motivation (Deci \& Ryan, 1985; Sørebø, Halvari, Gulli, \& Kristiansen, 2009; Vallerand, 1997). In technology-enhanced domains, this belief is associated with the users' perception about the available system, such as its usefulness and ease of use (Lee et al., 2015). Perceived usefulness of a system reflects the users' given value to that system for the improvement of their performance. Perceived usefulness of a system is considered to be an extrinsic motivation factor (Roca \& Gagné, 2008: 
Venkatesh, 1999), and in this study it was expected that perceived competence (an intrinsic motivation determinant) would influence perceived usefulness of the system (an extrinsic motivation determinant). Moreover, computer (Internet) self-efficacy has been shown to be associated with perceived ease of use of a system (Ho, 2010; Roca \& Gagné, 2008; Venkatesh \& Davis, 1996). Therefore, this study hypothesises that if Japanese EFL learners feel competent in using the available language learning technology beyond the classroom, in this case the web-based e-portfolio system, their perception of the system's usefulness and ease of use would be increased.

- H1. Learners' perceived competence positively predicts perceived usefulness of the system.

- H2. Learners’ perceived competence positively predicts perceived ease of use of the system.

Perceived autonomy reflects the individuals' desire to self-regulate their actions while using a technological tool, and perceived relatedness reflects their need to be connected to other members. In the same manner as perceived competence, the fulfilment of these two needs would enhance the learners' level of intrinsic and extrinsic motivation (Deci \& Ryan, 1985; Ryan \& Deci, 2000; Sørebø et al., 2009; Vallerand, 1997). Consequently, it was predicted that perceived usefulness of the system (i.e., extrinsic motivation) would be influenced by perceived autonomy and perceived relatedness. Based on the few previous studies that confirmed this relationship (Ho, 2010; Roca \& Gagné, 2008; Sørebø et al., 2009), it was also expected that if Japanese EFL learners feel a certain degree of control over their own actions and feel connected to their peers and instructors in using learning technologies, their satisfaction with the system and their perception of its usefulness would be enhanced. It should be noted that even though perceived competence is associated with perceived ease of use (Ho, 2010; Roca \& Gagné, 2008; Venkatesh \& Davis, 1996), there is not enough theoretical and empirical support for the relationship between perceived autonomy and perceived relatedness against perceived ease of use of a system. Therefore, because hypothesising relationships between these constructs could affect the entire model of the research, no hypotheses were formulated for the relationships between perceived autonomy and perceived relatedness against perceived ease of use.

- H3. Learners' perceived autonomy positively predicts perceived usefulness of the system.

- H4. Learners’ perceived relatedness positively predicts perceived usefulness of the system.

According to TAM, perceived ease of use can be a predictor of perceived usefulness of a system (Davis, 1989;; Park et al., 2014; Tarhini et al., 2015; Venkatesh \& Davis, 2000). Since perceived ease of use is considered a key determinant of perceived usefulness, it can also indirectly affect the intention to continue using a system through perceived usefulness. In other words, the system first needs to be handled easily in order to be perceived as useful and actually be implemented (Park et al., 2014). Therefore, this study forms the following hypothesis.

- H5. Learners' perceived ease of use of the e-portfolio system positively predicts perceived usefulness of the system.

The strong relationship between learners’ motivation and intention (Deci, 1975; Ellis, 1994; Lee et al., 2015; Pedrotti \& Nistor, 2016) indicates perceived usefulness as a form of extrinsic motivation can have a positive effect on users' behavioural intention to use a system (Davis, 1989). Consequently, this study hypothesises that Japanese EFL learners' perception of the usefulness of the web-based e-portfolio system predicts their intention to use the system for self-determined OCLL.

- H6. Learners' perceived usefulness of the e-portfolio system positively predicts their intention to continue OCLL.

Some studies indicate that perceived ease of use of a system positively influence the behavioural intention to use a system (Park, Roman, Lee, \& Chung, 2009; Venkatesh, 1999), whereas some other studies could not find any significant relationship between the two (Davis, 1989; Karahanna \& Straub, 1999; Park et al., 2014). This may be due to the fact that variables such as context, system, users and activities influence the basic 
relationships between TAM determinants (Park et al., 2014; Tarhini et al., 2015; Teo et al., 2008). Therefore, considering the users' effect (i.e., Japanese students) in terms of their low digital literacy, this study hypothesises that perceived ease of use of the e-portfolio system predicts Japanese EFL learners' behavioural intention to use the system for OCLL.

- H7. Learners' perceived ease of use of the e-portfolio system positively predicts their intention to continue technology-based OCLL.

Because of the difficulty of finding users' actual system usage, the relationship between the users' behavioural intention and their usage of the system has either been removed in TAM-based models or has been explored only through self-reported measures (Park et al., 2014; Venkatesh \& Davis, 2000). In their study, Venkatesh and Davis (2000) investigated that the intention of users to use a system significantly influences their actual usage of the system. Thus, this study hypothesises that Japanese EFL learners' intention to continue OCLL through the web-based e-portfolio system can positively predict their actual usage of the system.

- H8. Learners' behavioural intention to continue using the system for OCLL positively predicts their actual usage of the system.

\section{Research methodology}

\section{Participants}

The participants of this study were 162 EFL undergraduate Japanese students attending general English classes, majoring in engineering $\left(N_{\mathrm{e}}=31\right)$, law $\left(N_{\mathrm{l}}=56\right)$ and science $\left(N_{\mathrm{s}}=75\right)$. Students' ages ranged from 18 to $21(M=18.96, S D=.86)$, of whom $134(79.28 \%)$ were male. The majority of the students were freshmen (80.6\%), and the rest were sophomores. All the participants signed an informed consent form that explained the aim and procedure of the study at the beginning of the semester.

\section{Research context}

This study was conducted at one of the largest national Japanese universities that has a reputation for highquality ICT resources. The general English classes were held twice a week and each semester lasted for almost four months. The participants practised the reading skill of the TOEFL ITP ${ }^{\circledR}$ test in CALL classrooms using iBELLEs, an interactive blended English language learning enhancement system (Okada \& Sakamoto, 2015). Regarding the significant role of the OCLL, the learners were also provided with a web-based eportfolio system to enable them to continue reading practice autonomously beyond the classroom (Fathali \& Okada, 2016). Although the thorough explanation of the system function is beyond the purpose of this paper, the system is concisely described below.

The web-based e-portfolio system in this study is based on the idea of Reinders (2014), who emphasises that the efficient integration of virtual learning environments (VLEs) and personal learning environments (PLEs) results in transferring learners from VLEs to continue self-regulated learning through their own PLEs. Accordingly, the web-based e-portfolio system was designed with a combination of Google Sites as the collaborative VLE, and Google Drive as the learners' PLEs in order to enhance the learners' English reading proficiency. The proficiency enhancement was based on the selected principles of extensive reading explained by Day and Bamford (2002). It should be emphasised that in this study the term e-portfolio system refers to the combination of Google Sites with Google Drive, and the term e-portfolio refers to the students' individual works in Google Drive. 
The main website of the e-portfolio system consisted of web pages that supported learners' autonomous learning, such as:

- A page including a link to the Cambridge English language assessment website (http://www.cambridgeenglish.org/test-your-english/adult-learners/), which directed each learner to an online test, of which the final score was interpreted according to the Common European Framework of Reference for Languages (Council of Europe, 2001). The score helped the learners identify their level of English language proficiency and enabled them to independently find reading materials appropriate to their levels.

- A page including a list of appropriate websites for EFL learners such as TeachYa and cK-12.

- A page for the instructors' weekly feedbacks on the learners' assignments, in addition to the crucial points figured out through the weekly monitoring of the individual e-portfolios. The instructors tried to investigate common learning obstacles and eliminate them by referring the learners to different online training materials and informative websites.

- A page guiding the learners through self-assessment and setting future learning goals.

- A page in which all the learners' individual pages were brought together. Due to the large number of the students' pages, the pages were randomly put into groups for easier access. Each learner had an individual web page linked to his/her personal e-portfolio created in Google Drive. The individual pages enabled receiving instructor and peer feedback on the weekly assignments.

Each learner uploaded a weekly file of their reading practice, including the links to the passages they read and their preferred post-reading activities. Depending on the learners' preferences, the files could be of any type, such as Microsoft Office Word, PowerPoint, PDF, or image. In addition to the different post-reading activities on the web, such as word games, sentence matching, and multiple choice and open-ended questions, for more practice, the learners were instructed to do individual post-reading activities, such as writing summaries, listing newly learned words, and writing questions to help them actively interact with the texts (Rivas, 1999). Though the learners had access to all e-portfolios and could interact with each other on the website, they were also randomly assigned into pairs to ensure that everyone would at least have a partner for online interactions.

Overall, creating personal virtual spaces, having online interactions, knowing the informative websites - all these aimed to make the e-portfolio system a platform to lead the learners into the world of self-regulated use of web-based learning technologies.

\section{Measures}

The data was collected using an end-of-the-term online questionnaire in which the items were measured on a 7-point Likert scale ranging from 1 (strongly disagree) to 7 (strongly agree). The items were adapted from relevant measures used in previous studies with a few modifications in wording to reflect the target technology and domain. Learners' perceived competence was measured using five items adapted from the intrinsic motivation inventory (McAuley, Duncan, \& Tammen, 1989), of which a sample item was, "I think I was pretty good at learning English beyond the classroom using technology”. Learners' perceived autonomy was assessed through four items selected from Standage, Duda, and Ntoumanis (2005), with a sample item of "I felt a certain freedom of action in learning English beyond the classroom using technology". To measure learners' perceived relatedness five items from South's (2006) sense of community instrument were used with a sample item of "I felt that other classmates had similar goals to mine in learning English beyond the classroom using technology”. Perceived usefulness and perceived ease of use of the system were measured using eight items selected from Davis (1989) with the sample items of "I think using technology (e.g., eportfolio system) is very beneficial for independent language learning" (four items) and "I think it was easy for me to use technology (e.g., e-portfolio system) for language learning” (four items). Learners' intention to continue technology-enhanced OCLL was measured using three items adapted from Venkatesh, Morris, Davis, and Davis (2003), of which a sample item was "I intend to continue learning English beyond the classroom using technological devices (e.g., e-portfolio system)". Finally, learners' actual usage of the eportfolio system for OCLL was measured by the total number of eligible e-portfolio files in each learner's personal Google Drive, in addition to the frequency of his/her interactions on the e-portfolio system's website. 
The items of the questionnaire were adopted from previously published studies and believed to be reliable and valid. However, due to some modifications, the reliability of the constructs with the data of this study was tested using Cronbach's alpha reliability analysis (Table 1). The questionnaire was provided in English because the students were from one of the highest ranked Japanese national universities and they had all successfully passed very competitive English entrance examinations. In addition, the initial English language proficiency test indicated that the students' level was between B1 and B2, according to the Common European Framework of Reference for Languages (Council of Europe, 2001). However, in order to ensure that the items were clear and easy to understand, the questionnaire was first reviewed by two experts in the field and then it was piloted with 31 students. The piloting was conducted with the presence of the researchers, and the students were asked to identify any ambiguous items.

\section{Data analysis}

The internal consistency of the subscales of the questionnaire was examined using Cronbach's alpha reliability analysis. Exploratory factor analysis using the maximum likelihood technique was conducted to test the appropriateness of the items of each subscale (factors) of the research questionnaire. The primary advantage of maximum likelihood is that it "allows for the computation of a wide range of indexes of the goodness of fit of the model” (Fabrigar, Wegener, MacCallum, \& Strahan, 1999, p. 277). Confirmatory factor analysis was conducted to test some initial measurement models to ensure that the data of this study could support the proposed relationships, and to confirm the reliability and validity of the constructs in the measurement model. Composite reliability (CR) was computed to examine the reliability of the constructs in the measurement model which, according to Bagozzi and Yi (1988), should exceed 0.6. Convergent and discriminant validity were applied and tested according to Fornell and Larcker (1981), in which the convergent validity of the constructs is confirmed when all the items have factor loadings higher than 0.6 (Hulland, 1999), and discriminant validity is verified when the square root of the extracted average variance (AVE) greatly exceeds the correlation between each construct with the other constructs. Finally, path analysis was conducted to investigate the multivariate relations between the constructs in the hypothesised model using SPSS ${ }^{\circledR}$ AMOS. To estimate how well the initial model fit the data, according to Hair, Black, Babin, and Anderson (2010), five goodness of fit indices were evaluated: chi-square coefficient $\left(\chi^{2}\right)$, comparative fit index (CFI), Tucker-Lewis Index (TLI), standardized root mean square residual (SRMR), and root mean square error of approximation (RMSEA). The recommended values for the indices are presented in Table 3. The final structural model was created and analysed based on Kline's (2011) suggestion to use parcels. Kline defined a parcel as "a total score across a set of homogeneous items each with a Likert-type scale. Parcels are generally treated as continuous variables" (p. 179). Finally, actual use was added as the last continuous variable to the final structural model and the paths were analysed.

\section{Results}

The descriptive data of the questionnaire items including means, standard deviations, factor loadings, Cronbach's alpha coefficients, and CR are presented in Table 1. The results of the Cronbach's alpha reliability analysis indicated high internal consistency among the items of each subscale $(\alpha>0.8)$. The results of exploratory factor analysis indicated that six constructs were extracted with the total variance of the $64.27 \%$. It should be noted that perceived autonomy was measured through five items at the beginning, but due to the cross-factor loadings in the initial pattern matrix, one item was eliminated from the study. The satisfactory factor loadings of all the items in the questionnaire (higher than 0.6) confirmed the convergent validity of the constructs (Hulland, 1999). CR of each construct resulted in a good level of reliability for each construct (CR > .75). 
Table 1.

The descriptive statistics of the measurement constructs

\begin{tabular}{|c|c|c|c|c|c|c|c|}
\hline Construct & Item & Mean & SD & $\begin{array}{l}\text { Factor loadings } \\
\text { (EFA) }\end{array}$ & $\begin{array}{l}\text { Factor loadings } \\
\text { (CFA) }\end{array}$ & $\begin{array}{c}\text { Cronbach } \\
\alpha\end{array}$ & CR \\
\hline Perceived & & & & & & 0.89 & 0.89 \\
\hline \multirow[t]{5}{*}{ competence } & PComp_1 & 4.56 & .904 & .934 & .968 & & \\
\hline & PComp_2 & 4.74 & .875 & .861 & .877 & & \\
\hline & PComp_3 & 5.03 & .880 & .717 & .732 & & \\
\hline & PComp_4 & 4.87 & .927 & .663 & .671 & & \\
\hline & PComp_5 & 5.01 & .956 & .648 & .663 & & \\
\hline \multirow{5}{*}{$\begin{array}{l}\text { Perceived } \\
\text { autonomy }\end{array}$} & & & & & & 0.81 & 0.82 \\
\hline & PAut_1 & 4.71 & .922 & .763 & .771 & & \\
\hline & PAut_2 & 5.21 & .965 & .711 & .748 & & \\
\hline & PAut_3 & 4.63 & 1.03 & .698 & .726 & & \\
\hline & PAut_4 & 4.32 & 1.01 & .625 & .637 & & \\
\hline \multirow{6}{*}{$\begin{array}{l}\text { Perceived } \\
\text { relatedness }\end{array}$} & & & & & & 0.91 & 0.91 \\
\hline & PRel_1 & 4.24 & .889 & .889 & .912 & & \\
\hline & PRel_2 & 4.59 & .982 & .867 & .884 & & \\
\hline & PRel_3 & 4.11 & .721 & .818 & .823 & & \\
\hline & PRel_4 & 4.22 & .833 & .788 & .804 & & \\
\hline & PRel_5 & 4.08 & .848 & .683 & .699 & & \\
\hline \multirow{5}{*}{$\begin{array}{l}\text { Perceived } \\
\text { usefulness }\end{array}$} & & & & & & 0.94 & 0.89 \\
\hline & PU_1 & 5.99 & .775 & .944 & .954 & & \\
\hline & PU_2 & 5.93 & .776 & .911 & .926 & & \\
\hline & PU_3 & 5.92 & .791 & .792 & .829 & & \\
\hline & PU_4 & 5.91 & .766 & .798 & .817 & & \\
\hline \multirow{5}{*}{$\begin{array}{l}\text { Perceived } \\
\text { ease of use }\end{array}$} & & & & & & 0.91 & 0.87 \\
\hline & PEU_1 & 5.44 & .941 & .935 & .940 & & \\
\hline & PEU_2 & 5.42 & .940 & .844 & .858 & & \\
\hline & PEU_3 & 5.48 & .923 & .984 & .812 & & \\
\hline & PEU_4 & 5.69 & .826 & .718 & .738 & & \\
\hline \multirow[t]{4}{*}{ Intention } & & & & & & 0.87 & 0.79 \\
\hline & Int_1 & 6.02 & .541 & .822 & .840 & & \\
\hline & Int_2 & 5.63 & .636 & .659 & .687 & & \\
\hline & Int_3 & 5.75 & .703 & .639 & .646 & & \\
\hline
\end{tabular}


Correlations showed an adequate difference between the square root of the variance (AVE) and all other c orrelations for each construct; thus, the discriminant validity of the constructs was verified (Table 2). The results of the final fit of the measurement model (through confirmatory factor analysis) and the structural model considering the five fit indices suggested that the models had acceptable fit to the data (Table 3).

Table 2.

Correlation matrix and average variance extracted

\begin{tabular}{|c|c|c|c|c|c|c|}
\hline Construct & $\begin{array}{l}\text { Perceived } \\
\text { competence }\end{array}$ & $\begin{array}{l}\text { Perceived } \\
\text { autonomy }\end{array}$ & $\begin{array}{l}\text { Perceived } \\
\text { relatedness }\end{array}$ & $\begin{array}{l}\text { Perceived } \\
\text { usefulness }\end{array}$ & $\begin{array}{l}\text { Perceived } \\
\text { ease of use }\end{array}$ & Intention \\
\hline $\begin{array}{l}\text { Perceived } \\
\text { competence }\end{array}$ & $.582^{a}$ & & & & & \\
\hline $\begin{array}{l}\text { Perceived } \\
\text { autonomy }\end{array}$ & .384 & .631 & & & & \\
\hline $\begin{array}{l}\text { Perceived } \\
\text { relatedness }\end{array}$ & .401 & .335 & .683 & & & \\
\hline $\begin{array}{l}\text { Perceived } \\
\text { usefulness }\end{array}$ & .328 & .306 & .315 & .596 & & \\
\hline $\begin{array}{l}\text { Perceived ease of } \\
\text { use }\end{array}$ & .341 & .372 & .284 & .276 & .532 & \\
\hline Intention & .347 & .264 & .260 & .327 & .348 & .564 \\
\hline $\begin{array}{l}\text { Actual } \\
\text { performance }\end{array}$ & .359 & .285 & .251 & .302 & .283 & .276 \\
\hline
\end{tabular}

Table 3.

Model-fit indices for the measurement model and the structural model

\begin{tabular}{lccccccc}
\hline Model & $\chi^{2}(\boldsymbol{p}$ value $)$ & $\mathbf{d f}$ & $\chi^{2} / \mathbf{d f}$ & CFI & TLI & SRMR & RMSEA \\
\hline Measurement model & $398.342(p=.058)$ & 261 & 1.52 & .963 & .952 & .05 & .05 \\
Structural model & $191.538(p=.102)$ & 129 & 1.48 & .985 & .968 & .05 & .06 \\
Recommended values & $p>0.5$ & & $<3.0$ & $>.95$ & $>.95$ & $<.08$ & $<.08$ \\
\hline
\end{tabular}

Figure 2 presents the results of the final structural model with the standardised path coefficients. The results of the model suggest that $58 \%$ of the variance of the learners' intention for the technology-enhanced OCLL is explained by the determinants of SDT and TAM. The paths in Figure 2 indicate that perceived competence did positively influence perceived usefulness $(\beta=.25, p<0.01)$ and perceived ease of use of the system ( $\beta=.31, p<0.001$ ). Hence, the first two hypotheses of the research were supported by the model. The model reveals that perceived usefulness was influenced by the learners' perceived autonomy $(\beta=.18, p<0.05)$ and perceived relatedness $(\beta=.17, p<0.05)$. 


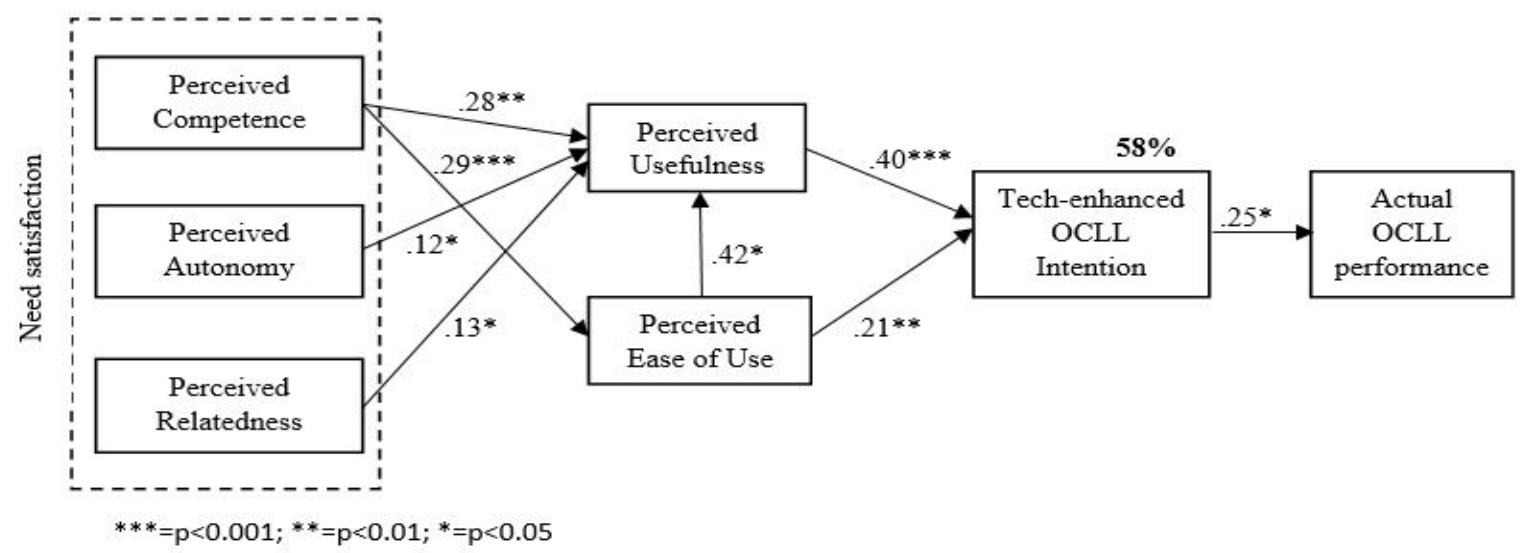

Figure. 2. Final structural model (standardised path coefficients)

Therefore, the model could support hypotheses 3 and 4. Perceived ease of use could also highly influence perceived usefulness of the system $(\beta=.42, p<0.01)$, supporting hypothesis 5 . The constructs of TAM, perceived usefulness $(\beta=.17, p<0.001)$ and perceived ease of use $(\beta=.17, p<0.01)$, were found to have significant effects on the learners' intention for technology-enhanced OCLL, which supported hypotheses 6 and 7 in the model. The final hypothesis of the research was also supported by the positive effect of the learners' intention for technology-enhanced language learning beyond the classroom as well as their actual usage of the system $(\beta=.25, p<0.01)$.

\section{Discussion}

The present study first proposed an extended model of the well-known TAM employing the motivation determinants introduced by SDT, and then empirically tested the relationship between the determinants in the hypothesised model to investigate how these determinants could explain Japanese EFL learners' intention to continue technology-enhanced OCLL, in addition to their actual usage of the learning technologies.

The findings of the study provide empirical supports for the hypothesised relationships between motivation and technology acceptance constructs. They support the hypothesised positive relationship between the learners' basic needs and the determinants that predict the acceptance of learning technologies. The findings indicated that satisfaction of the learners' basic needs for competence, autonomy, and relatedness that facilitate intrinsic motivation (Deci \& Ryan, 1985) positively predict the determinants of TAM, and in turn, TAM determinants significantly influence the learners' intention to carry out technology-enhanced OCLL as well as their actual performance on the system. The results indicated that $58 \%$ of the variance of the learners' intention for the technology-enhanced OCLL is explained by the determinants of SDT and TAM, which proves that the integration of TAM and SDT provides an appropriate framework for EFL technologyenhanced OCLL environments.

In line with previous studies that successfully implemented TAM and SDT in educational (Lee, et al., 2015; Nikou \& Economides, 2017) and work-related settings (Ho, 2010; Roca \& Gagné, 2008), this study found that in order to facilitate users' acceptance of a learning technology, which in turn strongly promotes their continuance intention to use technology, the fulfilment of the three basic psychological needs for competence, autonomy, and relatedness are of great importance. The degrees of the coefficient in the final research model show that among all the determinants of SDT, perceived competence plays the most important role in explaining perceived usefulness and perceived ease of use of the system. Perceived competence as a highly positive predictor of the learners' acceptance of the technology shows that feeling fully capable of using learning technologies is the most crucial factor in the context of technology-enhanced OCLL. Therefore, when Japanese EFL learners feel competent to use learning technologies, the possibility of accepting the 
learning technologies and their continuous usage would be highly maximised. This finding also reflects Japanese students' low digital literacy skills and their lack of confidence for using technology for learning.

Furthermore, the findings of the final research model indicate that this is also true for the learners' sense of autonomy and relatedness, though with lower degrees of coefficient. As shown in the model, the two motivational determinants, perceived autonomy and perceived relatedness, are positive predictors of Japanese EFL learners' intention to continue language learning beyond the classroom. This is also consistent with the findings by Ho (2010) and Roca and Gagné (2008). When it comes to autonomous learning, there is sometimes a misunderstanding that autonomous learning means individual learning in isolation. However, it is the learners' essential need to be guided and supported regularly while they are the ones who make the major decisions about learning (Benson, 2011; Thanasoulas, 2000). In Japan this may be neglected due to the Japanese students' vast use of digital technologies in everyday life and teachers' misperception that students can transfer their everyday life skills to their learning contexts without assistance. Moreover, OCLL can happen in different places and at different times; thus, one of its dominant characteristics is being disconnected from other learners. The results of the research model indicate that if the learning technologies enable the sense of connectedness to a community of other learners who share the same learning goals, they can maximise the acceptance of the learning technologies and the learners' intention to use them.

Previous studies showed contradictory findings for the relationship between perceived ease of use, perceived usefulness, and continuance intention of the learners. In some studies, perceived ease of use significantly contributed to both perceived usefulness and the continuance intention of the system users (Chung, Park, Wang, Fulk, \& McLaughlin, 2010; Park et al., 2014; Tarhini et al., 2015; Venkatesh \& Davis, 2000), while in other studies it did not have any significant effects (Lee \& Lehto, 2013; Liu, Li, \& Carlsson, 2010; Wang \& Wang, 2009). The findings of this study are in line with the first group of studies and indicate that perceived ease of use influenced perceived usefulness of the web-based e-portfolio system to a considerable degree. The results of the final model suggest that perceived ease of use significantly predicts the learners' continuance intention, both directly and indirectly through perceived usefulness. Accordingly, based on the findings of this study, it is believed that if Japanese learners feel less difficulty in working with the system, this feeling can contribute to their perception of the systems' potentials to facilitate their language learning, and they would be more willing to use the system beyond the classroom.

Although there are several studies scrutinising the relationship between the technology acceptance indicators and the behavioural intention of learners, there has been a serious gap in the literature about the relationship between behavioural intention and users' actual behaviour (Park et al., 2014; Venkatesh \& Davis, 2000). Little empirical research has been conducted to explore how users' intention to use a system predicts the actual usage of a system. Only in some studies this relationship is examined based on the self-reported usage measures, which may or may not be as accurate as actual usage measures (Straub, Limayem, \& KarahannaEvaristo, 1995; Taylor \& Todd, 1995). Therefore, this study examined the relationship between EFL learners' behavioural intention and their usage of the web-based e-portfolio system based on their actual performance on the system. The findings indicate that the Japanese EFL learners' intention to continue using a system can considerably predict their actual usage of the system for language learning.

\section{Conclusion and implications}

Since learners' potential acceptance of learning technologies and their continuance intention to use those technologies is a crucial and effective issue in OCLL contexts, this study investigated factors affecting learners' intention through the two frameworks of TAM and SDT. The results of the final model indicated meaningful relationships between the variables of SDT and TAM in the hypothesised model including perceived competence, perceived autonomy, perceived relatedness, perceived usefulness, perceived ease of use, continuance intention, and finally the actual usage of the system. So far there have been very few studies investigating the acceptance of learning technologies in OCLL environments. Previously the integration of these two frameworks proved to be appropriate in work-related settings, and this study as its first contribution to the literature reflected the applicability of this model to a technology-enhanced language learning context 
beyond the classroom, and furthermore, provided implications for researchers engaged in ICT domain and concerned with TAM-based studies.

In the constantly changing world of technology, the final goal should not be just implementing various learning technologies in education, but on finding proper ways to enhance the learners' continuance intention to use the learning technologies. The findings of this study have practical implications for EFL teachers and instructors by providing insights into the development of appropriate OCLL technologies. The study shows that teachers and instructors can implement learning technologies in a way that fulfills learners' motivational needs, such as the needs for competence, autonomy, and relatedness, and as a result they can maximize the potential usage of the technology. The significant effect of perceived competence in the model revealed that teachers and instructors can increase the usage of learning technologies by decreasing their complexity and providing adequate instructions. Not necessarily all the highly designed technology-enhanced learning environments result in continual lifelong learning. Linguistically, in Japanese, there is a particular pattern known as the volitional form, which specifically describes an intentional action. This pattern, in which the infinitive form of a verb 使う (tsukau; to use) changes to the volitional form 使おう(tsukaou; to be willing to use) indicates the speakers' intention and desire to set out doing an action. Thus, it is hoped that the development of technology-enhanced learning environments would be in a way to help learners reach the state of constant use of the volitional form, even if they are no longer connected to a specific learning community.

It is worth mentioning that the present study has some limitations. Since the core relationship between TAM determinants tend to be influenced by the context, nature of the system, users and activities (Park et al., 2014; Tarhini et al., 2015; Teo et al., 2008), the findings of this study may not be easily generalisable to all the technology-supported environments beyond the classroom. Moreover, the learners' achievements on the webbased e-portfolio system were measured by the number of learners' e-portfolio files and their interactions on the systems' website. Though this strategy was appropriate for the purpose of this study, other studies may be conducted using more rigid measurements of the learners' actual usage of the system.

\section{Acknowledgments}

This work was partially supported by Grant-in-Aid for Scientific Research (B) 26284075.

\section{References}

Abdullah, F., \& Ward, R. (2016). Developing a general extended technology acceptance model for e-learning (GETAMEL) by analysing commonly used external factors. Computers in Human Behavior, 56, $238-256$. https://doi.org/10.1016/j.chb.2015.11.036

Ajzen, I., \& Fishbein, M. (1980). Understanding attitudes and predicting social behaviour. Englewood Cliffs, NJ: Prentice-Hall.

Baard, P. P., Deci, E. L., \& Ryan, R. M. (2004). Intrinsic need satisfaction: A motivational basis of performance and well-being in two work settings. Journal of Applied Social Psychology, 34(10), 20452068. https://doi.org/10.1111/j.1559-1816.2004.tb02690.x

Bagozzi, R. P., \& Yi, Y. (1988). On the evaluation of structural equation models. Journal of the Academy of Marketing Science, 16(1), 74-94. https://doi.org/10.1177/009207038801600107

Bandura, A. (1986). Social foundations of thought and action: A social cognitive theory. Englewood Cliffs, NJ: Prentice-Hall.

Benson, P. (2001). Teaching and researching autonomy in language learning (1st ed.). Harlow: Longman.

Benson, P. (2011). Language learning and teaching beyond the classroom: An introduction to the field. In P. Benson \& H. Reinders (Eds.), Beyond the language classroom (1st ed., pp. 7-16). New York, NY: Palgrave Macmillan.

Chang, C. C., Yan, C. F., \& Tseng, J. S. (2012). Perceived convenience in an extended technology acceptance model: Mobile technology and English learning for college students. Australasian Journal of Educational Technology, 28(5), 809-826. https://doi.org/10.14742/ajet.818 
Chapelle, C. (2010). Evaluating computer technology for language learning. TESL-Ontario, 36(2), 56-67. Retrieved from https://www.teslontario.org/uploads/publications/researchsymposium/ResearchSymposium2010.pdf\#page $=56$

Chen, K. C., \& Jang, S. J. (2010). Motivation in online learning: Testing a model of self-determination theory. Computers in Human Behavior, 26(4), 741-752. https://doi.org/10.1016/j.chb.2010.01.011

Chung, J. E., Park, N., Wang, H., Fulk, J., \& McLaughlin, M. L. (2010). Age differences in perceptions of online community participation among non-users: An extension of the technology acceptance model. Computers in Human Behavior, 26(6), 1674-1684. https://doi.org/10.1016/j.chb.2010.06.017

Cote, T., \& Milliner, B. (2016). Japanese university students' self-assessment and digital literacy test results. In S. Papadima-Sophocleous, L. Bradley, \& S. Thouesny (Eds.), CALL Communities and Culture - Short Papers from EUROCALL (pp. 125-131). Dublin: Research-publishing.net.

Council of Europe. (2001). Common European framework of reference for languages: Learning, teaching, assessment. Cambridge: Cambridge University Press. Retrieved from http://www.coe.int/en/web/portfolio/principles-and-guidelines-and-cefr

Davis, F. D. (1989). Perceived usefulness, perceived ease of use, and user acceptance of information technology. MIS Quarterly, 13(3), 319-340. https://doi.org/10.2307/249008

Davis, F. D., Bagozzi, R. P., \& Warshaw, P. R. (1992). Extrinsic and intrinsic motivation to user computers in the workplaces. Journal of Applied Social Psychology, 22(14), 1111-1132. https://doi.org/10.1111/j.15591816.1992.tb00945.x

Day, R. R., \& Bamford, J. (2002). Top ten principles for teaching extensive reading. Reading in a Foreign Language, 14(2), 136-141. Retrieved from http://nflrc.hawaii.edu/rfl/October2002/day/day.pdf

Deci, E. L. (1975). Intrinsic motivation. New York, NY: Plenum Press.

Deci, E. L., \& Ryan, R. M. (1985). Intrinsic motivation and self-determination in human behavior (2nd ed.). New York, NY: Plenum Press.

Dornyei, Z. (1998). Motivation in second and foreign language learning. Language Teaching, 31(3), $117-135$. https://doi.org/10.1017/s026144480001315x

Edmunds, R., Thorpe, M., \& Conole, G. (2012). Student attitudes towards and use of ICT in course study, work and social activity: A technology acceptance model approach. British Journal of Educational Technology, 43(1), 71-84. https://doi.org/10.1111/j.1467-8535.2010.01142.x

Ellis, R. (1994). The study of second language acquisition. Oxford: Oxford University Press.

Fabrigar, L. R., Wegener, D. T., MacCallum, R. C., \& Strahan, E. J. (1999). Evaluating the use of exploratory factor analysis in psychological research. Psychological Methods, 4(3), 272-299. https://doi.org/10.1037//1082-989x.4.3.272

Fathali, S., \& Okada, T. (2016). On the importance of out-of-class language learning environments: A case of a web-based e-portfolio system enhancing reading proficiency. International Journal on Studies in English Language and Literature, 4(8), 77-85. https://doi.org/10.20431/2347-3134.0408011

Fornell, C., \& Larcker, D. F. (1981). Evaluating structural equation models with unobservable variables and measurement error. Journal of Marketing Research, 18(1), 39-50. https://doi.org/10.2307/3151312

Fukuda, S. T., \& Yoshida, H. (2013). Time is of the essence: Factors encouraging out-of-class study time. ELT Journal, 67(1), 31-40. https://doi.org/10.1093/elt/ccs054

Gobel, P., \& Kano, M. (2014). Mobile natives, Japanese university students’ use of digital technology. In J. B. Son (Ed.), Computer-assisted language learning: Learners, teachers and tools (1st ed., pp. 21-46). Newcastle upon Tyne: Cambridge Scholars Publishing.

Grabe, W. (2009). Reading in a second language: Moving from theory to practice. New York, NY: Cambridge University Press.Hair, J., Black, W., Babin, B., \& Anderson, R. (2010). Multivariate data analysis (7th ed.). Upper Saddle River, NJ: Prentice Hall.

Ho, C. H. (2010). Continuance intention of e-learning platform: Toward an integrated model. International Journal of Electronic Business Management, 8(3), 206-215. Retrieved from ProQuest database. (Accession No. 237699)

Hulland, J. (1999). Use of partial least squares (PLS) in strategic management research: A review of four recent studies. Strategic Management Journal, 20(2), 195-204. https://doi.org/10.1002/(sici)1097$\underline{\text { 0266(199902)20:23.0.co;2-7 }}$ 
International Telecommunication Union. (2017). ICT development index. Retrieved from http://www.itu.int/net4/ITU-D/idi/2017/index.html

Karahanna, E., \& Straub, D. W. (1999). The psychological origins of perceived usefulness and ease-of-use. Information and Management, 35(4), 237-250. https://doi.org/10.1016/s0378-7206(98)00096-2

Kline, R. B. (2011). Principles and practice of structural equation modeling (2nd ed.). New York, NY: Guilford Press.

Lai, C., Li, X., \& Wang, Q. (2017). Students’ perceptions of teacher impact on their self-directed language learning with technology beyond the classroom: Cases of Hong Kong and U.S. Educational Technology Research and Development, 29(4), 703-723. https://doi.org/10.1007/s11423-017-9523-4

Lee, D. Y., \& Lehto, M. R. (2013). User acceptance of YouTube for procedural learning: An extension of the Technology Acceptance Model. Computers \& Education, 61, 193-208. https://doi.org/10.1016/j.compedu.2012.10.001

Lee, Y., Lee, J., \& Hwang, Y. (2015). Relating motivation to information and communication technology acceptance: Self-determination theory perspective. Computers in Human Behavior, 51, 418-428. https://doi.org/10.1016/j.chb.2015.05.021

Li, Y., \& Huang, J. (2009). Applying theory of perceived risk and technology acceptance model in the online shopping channel. World Academy of Science, Engineering and Technology, 53(1), 919-925. Retrieved from https://waset.org/publications/15733/applying-theory-of-perceived-risk-and-technology-acceptancemodel-in-the-online-shopping-channel

Liu, Y., Li, H., \& Carlsson, C. (2010). Factors driving the adoption of m-learning: An empirical study. Computers \& Education, 55(3), 1211-1219. https://doi.org/10.1016/j.compedu.2010.05.018

Lockley, T., \& Promnitz-Hayashi, L. (2012). Japanese university students’ CALL attitudes, aspirations and motivations. CALL-EJ, 13(1), 1-16. Retrieved from http://callej.org/archives.html

McAuley, E., Duncan, T., \& Tammen, V. V. (1989). Psychometric properties of the intrinsic motivation inventory in a competitive sport setting: A confirmatory factor analysis. Research Quarterly for Exercise and Sport, 60(1), 48-58. https://doi.org/10.1080/02701367.1989.10607413

Mobarhan, R., Majidi, M., \& Abdul Rahman, A. (2014). Motivation in electronic portfolio usage for higher education institutions. In H. Rahman \& R. D. Sousa (Eds.), Information systems and technology for organizational agility, intelligence, and resilience (1st ed., pp. 224-243). Hershey, PA: IGI Global.

Muthitacharoen, A., Pallvia, P. C., Brooks, L. D., Krishnan, B. C., Otondo, R. F., \& Retzlaff-Robert, D. (2006). Reexamining technology acceptance in online task behaviors. Electronic Markets, 16(1), 4-15. https://doi.org/10.1080/10196780500491063

Nikou, S. A., \& Economides, A. A. (2017). Mobile-based assessment: Integrating acceptance and motivational factors into a combined model of Self-determination theory and technology acceptance. Computers in Human Behavior, 68, 83-95. https://doi.org/10.1016/j.chb.2016.11.020

Nunan, D., \& Richards, J. C. (Eds.). (2015). Language learning beyond the classroom. New York, NY: Routledge.

Okada, T., \& Sakamoto, Y. (2015). Dynamic lesson planning in EFL reading classes through a new e-learning system. In F. Helm, L. Bradley, M. Guarda, \& S. Thouësny (Eds.), Critical CALL. Proceedings of the 2015 EUROCALL Conference (pp. 444-449). Dublin: Research publishing.net. https://doi.org/10.14705/rpnet.2015.000373

Padilla-MeléNdez, A., Del Aguila-Obra, A. R., \& Garrido-Moreno, A. (2013). Perceived playfulness, gender differences and technology acceptance model in a blended learning scenario. Computers \& Education, 63, 306-317. https://doi.org/10.1016/j.compedu.2012.12.014

Park, N., Rhoads, M., Hou, J., \& Lee, K. M. (2014). Understanding the acceptance of teleconferencing systems among employees: An extension of the technology acceptance model. Computers in Human Behavior, 39, 118-127. https://doi.org/10.1016/j.chb.2014.05.048

Park, N., Roman, R., Lee, S., \& Chung, J. E. (2009). User acceptance of a digital library system in developing countries: An application of the technology acceptance model. International Journal of Information Management, 29(3), 196-209. https://doi.org/10.1016/j.ijinfomgt.2008.07.001

Pedrotti M., Nistor N. (2016). User Motivation and Technology Acceptance in Online Learning Environments. In K. Verbert, M. Sharples, \& T. Klobučar (Eds.), Adaptive and adaptable learning (pp. 472-477). Cham: Springer. 
Pintrich, P., \& Schunk, D. (2002). Motivation in education: Theory, research, and application (2nd ed.). Upper Saddle River, NJ: Prentice-Hall.

Reinders, H. (2014). Personal learning environments for supporting out-of-class language learning. English Teaching Forum, 52( 4), 14-19. Retrieved from http://unitec.researchbank.ac.nz/handle/10652/2964

Richards, J. C. (2015). The changing face of language learning: Learning beyond the classroom. RELC Journal, 46(1), 5-22. https://doi.org/10.1177/0033688214561621

Rivas, R. M. M. (1999). Reading in recent ELT course books. ELT Journal, 53(1), 12-21. https://doi.org/10.1093/elt/53.1.12

Roca, J. C., \& Gagné, M. (2008). Understanding e-learning continuance intention in the workplace: A selfdetermination theory perspective. Computers in Human Behavior, 24(4), 1585-1604. https://doi.org/10.1016/j.chb.2007.06.001

Ryan, R. M., \& Deci, E. L. (2000). Self-determination theory and the facilitation of intrinsic motivation, social development, and well-being. American Psychologist, 55(1), 68-78. https://doi.org/10.1037//0003066x.55.1.68

Schunk. D., \& Zimmerman, B. (2006). Competence and control beliefs: Distinguishing the means and the ends. In P. Alexander \& P. Winne (Eds.), Handbook of educational psychology (2nd ed., pp. 349-367). Mahwah, NJ: Lawrence Erlbaum Associates.

Sørebø, Ø., Halvari, H., Gulli, V. F., \& Kristiansen, R. (2009). The role of self-determination theory in explaining teachers' motivation to continue to use e-learning technology. Computers \& Education, 53(4), 1177-1187. https://doi.org/10.1016/j.compedu.2009.06.001

South, S. E. (2006). Contributing factors to engagement in online learning environments: The relationship between sense of community and participation (Doctoral dissertation). University of Arizona, United States. Retrieved from http://arizona.openrepository.com/arizona/handle/10150/194816

Standage, M., Duda, J. L., \& Ntoumanis, N. (2005). A test of self-determination theory in school physical education. British Journal of Educational Psychology, 75(3), 411-433. https://doi.org/10.1348/000709904x22359

Steel, C. H., \& Levy, M. (2013). Language students and their technologies: Charting the evolution 20062011. ReCALL, 25(3), 306-320. https://doi.org/10.1017/s0958344013000128

Stockwell, G. (2013). Tracking learner usage of mobile phones for language learning outside of the classroom. In P. Hubbard, M. Schulz, \& B. Smith (Eds.), Learner-computer interaction in language education: A festschrift in honor of Robert Fischer (pp. 118-136). San Marcos, TX: CALICO.

Straub, D., Limayem, M., \& Karahanna-Evaristo, E. (1995). Measuring system usage: Implications for IS theory testing. Management Science, 41(8), 1328-1342. https://doi.org/10.1287/mnsc.41.8.1328

Tarhini, A., Scott, M., Sharma, S., \& Abbasi, M. (2015). Differences in intention to use educational RSS feeds between Lebanese and British students: A multi-group analysis based on the technology acceptance model. The Electronic Journal of e-Learning, 13(1), 14-29. Retrieved from http://www.ejel.org/volume13/issue1

Taylor, S., \& Todd, P. A. (1995). Understanding information technology usage: A test of competing models. Information Systems Research, 6 (2), 144-176. https://doi.org/10.1287/isre.6.2.144

Teo, T., Luan, W. S., \& Sing, C. C. (2008). A cross-cultural examination of the intention to use technology between Singaporean and Malaysian pre-service teachers: An application of the Technology Acceptance Model (TAM). Journal of Educational Technology and Society, 11(4), 265-280. Retrieved from http://www.learntechlib.org/p/75056/

Thanasoulas, D. (2000). What is learner autonomy and how can it be fostered. The Internet TESL Journal, 6(11), 37-48. Retrieved from http://iteslj.org/Articles/Thanasoulas-Autonomy.html

Thomas, M. (2017). Project-based language learning with technology: Learner collaboration in an EFL classroom in Japan (1st ed.). New York, NY: Routledge.

Vallerand, R. J. (1997). Toward a hierarchical model of intrinsic and extrinsic motivation. Advances in Experimental Social Psychology, 29, 271-360. https://doi.org/10.1016/s00652601(08)60019-2

Venkatesh, V. (1999). Creation of favorable user perceptions: Exploring the role of intrinsic motivation. MIS Quarterly, 23(2), 239-260. https://doi.org/10.2307/249753

Venkatesh, V., \& Davis, F. D. (1996). A model of the antecedents of perceived ease of use: Development and test. Decision Sciences, 27(3), 451-481. https://doi.org/10.1111/j.1540-5915.1996.tb00860.x 
Venkatesh, V., \& Davis, F. D. (2000). A theoretical extension of the technology acceptance model: Four longitudinal field studies. Management Science, 46(2), 186-204. https://doi.org/10.1287/mnsc.46.2.186.11926

Venkatesh, V., Morris, M., Davis, G., \& Davis, F. (2003). User acceptance of information technology: Toward a unified view. MIS Quarterly, 27(3), 425-478.

Wang, W. T., \& Wang, C. C. (2009). An empirical study of instructor adoption of web-based learning systems. Computers \& Education, 53(3), 761-774. https://doi.org/10.1016/j.compedu.2009.02.021

Whittaker, C. (2013). A military blend. In B. Tomlinson \& C. Whittaker (Eds.), Blended learning in English language teaching: Course design and implementation (1st ed., pp. 175-183). London: British Council.

Yoon, C., \& Rolland, E. (2012). Knowledge-sharing in virtual communities: Familiarity, anonymity and selfdetermination theory. Behavior \& Information Technology, 31(11), 1133-1143. https://doi.org/10.1080/0144929x.2012.702355

Zhao, Y., \& Lai, C. (2007). Technology and second language learning: Promises and problems. In L. L. Parker (Ed.), Technology-mediated learning environments for young English learners: Connections in and out of school (pp. 167-205). Mahwah, NJ: Lawrence Erlbaum Associates.

Zhou, M. (2016). Chinese university students' acceptance of MOOCs: A self-determination perspective. Computers \& Education, 92, 194-203. https://doi.org/10.1016/j.compedu. 2015.10.012

Corresponding author: Somayeh Fathali, s.fathali685@gmail.com

Australasian Journal of Educational Technology @ 2018.

Please cite as: Fathali, S., \& Okada, T. (2018). Technology acceptance model in technology-enhanced OCLL contexts: A self-determination theory approach. Australasian Journal of Educational Technology, 34(4), 138-154. https://doi.org/10.14742/ajet.3629 